\title{
Association of the beta-1 adrenergic receptor carboxyl terminal variants with left ventricular hypertrophy among diabetic and non-diabetic survivors of acute myocardial infarction
}

\author{
Anna E Hakalahti ${ }^{{ }^{*}}$, Jari M Tapanainen ${ }^{2}$, Juhani M Junttila ${ }^{3}$, Kari S Kaikkonen ${ }^{3}$, Heikki V Huikuri ${ }^{3}$, Ulla E Petäjä-Repo ${ }^{1}$
}

\begin{abstract}
Background: The beta- 1 adrenergic receptor $\left(\beta_{1} A R\right)$ plays a fundamental role in the regulation of cardiovascular functions. It carries a nonsynonymous single nucleotide polymorphism in its carboxyl terminal tail (Arg389Gly), which has been shown to associate with various echocardiographic parameters linked to left ventricular hypertrophy $(\mathrm{LVH})$. Diabetes mellitus (DM), on the other hand, represents a risk factor for $\mathrm{LVH}$. We investigated the possible association between the Arg389Gly polymorphism and LVH among non-diabetic and diabetic acute myocardial infarction (AMI) survivors.
\end{abstract}

Methods: The study population consisted of 452 AMI survivors, $20.6 \%$ of whom had diagnosed DM. Left ventricular parameters were measured with two-dimensional guided M-mode echocardiography 2-7 days after AMI, and the Arg389Gly polymorphism was determined using a polymerase chain reaction-restriction fragment length polymorphism assay.

Results: The Arg389 homozygotes in the whole study population had a significantly increased left ventricular mass index (LVMI) when compared to the Gly389 carriers (either Gly389 homozygotes or Arg389/Gly389 heterozygotes) [62.7 vs. 58.4, respectively ( $p=0.023)]$. In particular, the Arg389 homozygotes displayed thicker diastolic interventricular septal (IVSd) measures when compared to the Gly389 carriers [13.2 vs. $12.3 \mathrm{~mm}$, respectively $(p=0.004)]$. When the euglycemic and diabetic patients were analyzed separately, the latter had significantly increased LVMI and diastolic left ventricular posterior wall (LVPWd) values compared to the euglycemic patients $[\mathrm{LVMI}=69.1$ vs. $58.8(\mathrm{p}=0.001)$ and LVPWd $=14.2$ vs. $12.3 \mathrm{~mm}(\mathrm{p}<0.001)$, respectively]. Furthermore, among the euglycemic patients, the Arg389 homozygotes displayed increased LVMI and IVSd values compared to the Gly389 carriers [LVMI $=60.6$ vs. 56.3 , respectively ( $p=0.028$ ) and IVSd $=13.1$ vs. $12.0 \mathrm{~mm}$, respectively $(p=0.001)$ ]. There was no difference in the LVMI and IVSd values between the diabetic Arg389 homozygotes and Gly389 carriers.

Conclusions: The data suggest an association between the $\beta_{1}$ AR Arg389Gly polymorphism and LVH, particularly the septal hypertrophy. The Arg389 variant appears to confer a higher risk of developing LVH than the corresponding Gly389 variant among patients who have suffered AMI. This association cannot be considered to be universal, however, since it does not appear to exist among diabetic AMl survivors.

\footnotetext{
* Correspondence: anna.hakalahti@oulu.fi

'Institute of Biomedicine, Department of Anatomy and Cell Biology,

University of Oulu, P.O. Box 5000, Fl-90014 Oulu, Finland

Full list of author information is available at the end of the article
} 


\section{Background}

Cardiac left ventricular hypertrophy (LVH) is an important risk factor for an adverse outcome in patients both with or without coronary artery disease [1]. Furthermore, LVH represents an independent risk factor for sudden cardiac death, congestive heart failure, coronary heart disease and stroke, and it has been associated with diabetes mellitus (DM) and glucose intolerance in several epidemiological investigations [2-6]. On the other hand, LVH can also be explained by genetic factors [7-9] and its heritability has been estimated to be 0.17 0.69 [10-12].

The beta- 1 adrenergic receptor $\left(\beta_{1} \mathrm{AR}\right)$ has been considered to represent a potential candidate gene for LVH [12-15]. This G protein-coupled receptor is the predominant beta adrenergic receptor in the heart $\left(\sim 70 \% \beta_{1} \mathrm{AR}\right.$ and $\left.30 \% \beta_{2} \mathrm{AR}\right)$, maintaining cardiac contractility in response to endogenous catecholamines [16]. The $\beta_{1} \mathrm{AR}$ gene is localized to $10 \mathrm{q} 24-26$ [17] and was cloned in 1987 [18]. It encodes a 477-amino acid membrane protein that carries two common nonsynonymous single nucleotide polymorphisms, one in the extracellular amino terminus (Ser49Gly) and another in the proximal carboxyl terminus (Arg389Gly) [19]. The Arg389Gly polymorphic site lies within the putative $G_{s}$ coupling domain of the receptor [20]. It has thus been considered to have functional significance, because the positively charged arginine residue differs markedly from neutral glycine. Accordingly, the polymorphism has been shown to have an effect on signalling properties of the receptor [21].

The aim of our study was to investigate the possible association of the $\beta_{1} \mathrm{AR}$ Arg389Gly polymorphism with various variables, including cardiac left ventricular parameters, among acute myocardial infarction (AMI) survivors in Northern Finland. We analyzed 452 patients, $20.6 \%$ of whom had diagnosed DM.

\section{Methods}

\section{Patient population}

The study population was recruited in 1996-2000. This single-center, prospective study, the Multiple Risk Factor Analysis Trial, was carried out at the Institute of Clinical Medicine, Department of Internal Medicine, Division of Cardiology, University of Oulu [22]. The aim of the study was to determine the prognostic power of several non-invasive risk markers of mortality among AMI survivors. A total of 452 consecutive series of patients who had undergone AMI were investigated for the $\beta_{1} A R$ Arg389Gly polymorphism. The patients were recruited to participate in the study during the first week after the AMI diagnosis, which was confirmed by using the contemporary guidelines at the beginning of the study. The exclusion criteria and qualifying diagnosis have been described previously [22].

\section{Biometric and laboratory methods}

Height and weight were measured for each patient by a registered nurse. Body mass index (BMI) was obtained from the ratio of weight $(\mathrm{kg})$ to height squared $\left(\mathrm{m}^{2}\right)$. Blood pressure was obtained in a supine position by a registered nurse following a five minute resting period. Blood samples were collected from the patients after an overnight fast. The fasting glucose, total cholesterol, HDL cholesterol, LDL cholesterol and triglyceride levels were measured at the Institute of Diagnostics, Department of Clinical Chemistry at Oulu University Hospital using standard enzymatic methods.

\section{Genotyping}

The $\beta_{1}$ AR Arg389Gly polymorphism was determined by using a polymerase chain reaction-restriction fragment length polymorphism assay, a modified PCR-technique described previously by Maqbool [19]. The restriction endonuclease Bcg I used in the protocol was from New England BioLabs (Beverly, MA, USA). The genotyping was performed in 2009 using DNA samples which had been stored at $-20^{\circ} \mathrm{C}$.

\section{Echocardiography and variable calculation}

Left ventricular parameters were measured within 2-7 days after AMI. Echocardiographic studies were performed at the Institute of Clinical Medicine, Department of Internal Medicine, Division of Cardiology at Oulu University Hospital. Left ventricular internal dimension (LVID), interventricular septal thickness (IVS) and left ventricular posterior wall thickness (LVPW) were measured at end-diastole (d) and end-systole (s). The parameters were measured with two-dimensional guided M-mode echocardiography following the American Society of Cardiology/American Heart Association guidelines. Considering each parameter, three distinct measurements were done and the averages were calculated.

Left ventricular mass (LVM) was calculated from LVIDd, LVPWd and IVSd using the equation originally described by Devereux and colleagues [23]. This method gives values, which have been confirmed to be closely related to the necropsy left ventricular weight. To obtain LVMI, LVM was divided by height ${ }^{2.7}$.

\section{Data analysis}

Statistical analyses were performed with SPSS 17.0/ PASW 18.0 software packages and where appropriate, power calculations were performed with SamplePower 2.0. In the power calculations, alpha was set as 0.05 . The Hardy-Weinberg equilibrium was tested with the 
$\mathrm{X}^{2}$ test. Student's two-tailed t-test was used to compare the quantitative parameters (expressed as means \pm S.D) between the groups, respectively. Categorical variables were compared using the $\mathrm{X}^{2}$ analysis. Analysis of covariance (ANCOVA) was used for comparison of the echocardiographic variables between the genotype groups (expressed as means \pm S.D). Using ANCOVA, the $\beta_{1}$ AR Arg389Gly polymorphism was set as a fixed factor. Age and BMI were added as co-variables to adjust the results. $\mathrm{P}<0.05$ was considered statistically significant. Nominal p values are presented throughout, i.e. without correction for multiple testing, as recommended by Rothman [24].

\section{Results}

\section{Characteristics of the AMI population}

The main clinical and biochemical data of the study population are shown in Table 1, in which the euglycemic and diabetic patients have been analyzed separately. As expected, the euglycemic and diabetic subgroups differed in many clinical aspects in addition to the history of DM and fasting glucose. There were significantly more women among the diabetic group, and the mean age as well as BMI and fasting triglycerides were higher as compared to the euglycemic group. Among the diabetic patients, the prevalence of congestive heart failure was significantly greater, and therefore the use of diuretics and digoxin, and partly angiotensin-converting enzyme inhibitors or sartans, was more frequent than among the euglycemic individuals. Table 2 shows the echocardiographic parameters, again analyzed separately for the euglycemic and diabetic subgroups. As expected [2-6], LVMI, and also LVPWd values were significantly higher among the diabetic patients when compared to the euglycemic individuals. Power calculations revealed the power to detect differences between the euglycemic and diabetic patients 100\% for both LVMI and LVPWd.

\section{Arg389Gly allele and genotype frequencies}

The $\beta_{1}$ AR genotype at codon 389 was determined in 452 AMI survivors. The allele frequencies were 0.75 for Arg389 and 0.25 for Gly389. These values were in accordance with frequencies observed in other Caucasian populations [25-27]. The frequencies of subjects homozygous for the Arg389 or Gly389 alleles were 0.57 and 0.07 . The genotype frequencies were also in line with previous European studies [26,27]. The study population was in Hardy-Weinberg equilibrium $\left(\mathrm{X}^{2}=0.817\right)$.

Table 1 Clinical and biochemical characteristics of the euglycemic and diabetic patients in the study population

\begin{tabular}{|c|c|c|c|c|}
\hline & $\begin{array}{l}\text { Total } \\
\mathrm{n}=452 \\
\end{array}$ & $\begin{array}{l}\text { Euglycemic patients } \\
\mathrm{n}=359(79.4 \%)\end{array}$ & $\begin{array}{l}\text { Diabetic patients } \\
\mathrm{n}=93(20.6 \%)\end{array}$ & $p$ value \\
\hline Gender (male/female) & $354 / 98(78.3 / 21.7 \%)$ & 289/70 (80.5/19.5\%) & $65 / 28(69.9 / 30.1 \%)$ & 0.027 \\
\hline Age (years) & $60.8 \pm 9.7$ & $60.0 \pm 9.5$ & $63.8 \pm 9.8$ & 0.001 \\
\hline BMI & $27.5 \pm 3.8$ & $27.3 \pm 3.6$ & $28.4 \pm 4.4$ & 0.014 \\
\hline Height (cm) & $170.4 \pm 8.4$ & $170.6 \pm 8.1$ & $169.4 \pm 9.4$ & NS \\
\hline Weight (kg) & $79.9 \pm 13.2$ & $79.6 \pm 13.2$ & $81.2 \pm 13.2$ & NS \\
\hline SBP (supine mmHg) & $123.2 \pm 19.1$ & $122.7 \pm 18.7$ & $125.7 \pm 20.7$ & NS \\
\hline DBP (supine mmHg) & $80.2 \pm 10.9$ & $80.5 \pm 10.9$ & $79.0 \pm 11.2$ & NS \\
\hline Congestive heart failure & 45 (10.0\%) & $16(4.5 \%)$ & $29(31.2 \%)$ & $<0.001$ \\
\hline \multicolumn{5}{|l|}{ Concomitant medications } \\
\hline Acetylsalicylic acid & $392(86.7 \%)$ & 317 (88.3\%) & $75(80.6 \%)$ & NS \\
\hline Beta blocker & $440(97.3 \%)$ & $348(96.9 \%)$ & $92(98.9 \%)$ & NS \\
\hline ACE inhibitor/sartan & $179(37.6 \%)$ & $123(34.3 \%)$ & $47(50.5 \%)$ & 0.004 \\
\hline Diuretic & $87(19.2 \%)$ & $50(13.9 \%)$ & 37 (39.8\%) & $<0.001$ \\
\hline Calcium channel blocker & $26(5.8 \%)$ & $21(5.8 \%)$ & $5(5.4 \%)$ & NS \\
\hline Statin & $176(38.9 \%)$ & $140(39.0 \%)$ & $36(38.7 \%)$ & NS \\
\hline Warfarin & $36(8.0 \%)$ & $28(7.8 \%)$ & $8(8.6 \%)$ & NS \\
\hline Digoxin & $19(4.2 \%)$ & $10(2.8 \%)$ & $9(9.7 \%)$ & 0.003 \\
\hline Amiodarone & $6(1.3 \%)$ & $6(1.7 \%)$ & $0(0 \%)$ & NS \\
\hline Fasting glucose (mmol/l) & $6.4 \pm 2.1$ & $5.9 \pm 1.4$ & $8.3 \pm 2.9$ & $<0.001$ \\
\hline Total cholesterol (mmol/l) & $5.4 \pm 3.4$ & $5.4 \pm 3.7$ & $5.3 \pm 1.2$ & NS \\
\hline HDL cholesterol (mmol/l) & $1.1 \pm 0.3$ & $1.2 \pm 0.3$ & $1.1 \pm 0.3$ & NS \\
\hline LDL cholesterol (mmol/l) & $3.4 \pm 0.9$ & $3.4 \pm 0.9$ & $3.4 \pm 1.1$ & NS \\
\hline Triglycerides (mmol/l) & $1.6 \pm 0.9$ & $1.5 \pm 0.9$ & $2.0 \pm 1.1$ & $<0.001$ \\
\hline
\end{tabular}

Student's two-tailed t-test (quantitative variables) or $\mathrm{X}^{2}$ analysis (categorical variables) was performed to compare the populations. BMI, body mass index; SBP, systolic blood pressure; DBP, diastolic blood pressure; ACE, angiotensin-converting enzyme; NS, not significant. Data for continuous variables are presented as mean \pm S.D. Categorical variables are presented as number of subjects and as percentages (in parentheses). 
Table 2 Echocardiographic variables of the euglycemic and diabetic patients in the study population

\begin{tabular}{lllll}
\hline & $\begin{array}{l}\text { Total } \\
\mathbf{n = 4 5 2}\end{array}$ & $\begin{array}{l}\text { Euglycemic } \\
\text { patients } \\
\mathbf{n = 3 5 9}(\mathbf{7 9 . 4 \% )}\end{array}$ & $\begin{array}{l}\text { Diabetic } \\
\text { patients } \\
\mathbf{n = 9 3}(\mathbf{2 0 . 6 \% )}\end{array}$ & $\begin{array}{l}\mathbf{p} \\
\text { value }\end{array}$ \\
\hline LVMI & $60.9 \pm$ & $58.8 \pm 18.3$ & $69.1 \pm 21.7$ & 0.001 \\
& 19.4 & & $13.4 \pm 3.3$ & NS \\
IVSd (mm) & $12.8 \pm 3.0$ & $12.7 \pm 2.8$ & $50.5 \pm 7.1$ & NS \\
LVIDd & $49.8 \pm 7.1$ & $49.6 \pm 7.1$ & $14.2 \pm 5.3$ & $<$ \\
$(\mathrm{mm})$ & & & & 0.001 \\
LVPWd & $12.7 \pm 3.6$ & $12.3 \pm 2.9$ & $44.8 \pm 9.4$ & $\mathrm{NS}$ \\
\hline (mm) & & & $46.3 \pm 8.4$ &
\end{tabular}

ANCOVA was performed to compare the groups. The polymorphism was set as a fixed factor. Age and BMI were added as co-variables to adjust the results. LVMI, left ventricular mass index; IVSd, interventricular septal thickness at end-diastole; LVIDd, left ventricular internal dimension at end-diastole; LVPWd, left ventricular posterior wall thickness at end-diastole; EF, ejection fraction. Data are presented as mean \pm S.D.

\section{Arg389Gly polymorphism and echocardiographic} parameters

The echocardiographic parameters according to the Arg389Gly polymorphism in the whole study population are listed in Table 3. The Arg389 homozygotes were found to have significantly increased mean LVMI when compared to the Gly389 carriers ( $\mathrm{p}=0.023)$. In particular, the Arg389 homozygotes displayed thicker IVSd measures when compared to the Gly389 carriers ( $\mathrm{p}=$ $0.004)$. Power calculations indicated that the study sample had $67 \%$ power to detect differences in LVMI between the Arg389 homozygotes and the Gly389 carriers. Furthermore, power calculations showed that the required sample size for the achievement of power equal to $80 \%$ would be 580 subjects. For IVSd, the power was calculated to be $90 \%$.

Table 4 shows the echocardiographic variables according to the Arg389Gly polymorphism analyzed in the euglycemic patients. The Arg389 homozygotes displayed increased LVMI values compared to the Gly389 carriers $(\mathrm{p}=0.028)$. Again, particularly the IVSd values were

Table 3 Echocardiographic variables in the whole study population according to the $\beta_{1}$ AR Arg389 homozygotes and Gly389 carriers

\begin{tabular}{llll}
\hline & $\begin{array}{l}\text { Total } \\
\mathbf{n}=\mathbf{4 5 2} \\
\text { Arg homozygotes } \\
\mathbf{n = 2 5 8}(\mathbf{5 7 . 1 \% )}\end{array}$ & $\begin{array}{l}\text { Gly carriers } \\
\mathbf{n = 1 9 4}(\mathbf{4 2 . 9 \% )}\end{array}$ & p value \\
\hline LVMI & $62.7 \pm 19.1$ & $58.4 \pm 19.8$ & 0.023 \\
IVSd (mm) & $13.2 \pm 3.1$ & $12.3 \pm 2.7$ & 0.004 \\
LVIDd (mm) & $49.8 \pm 7.3$ & $49.9 \pm 6.7$ & NS \\
LVPWd (mm) & $12.9 \pm 3.6$ & $12.5 \pm 3.6$ & NS \\
EF & $45.9 \pm 8.7$ & $46.2 \pm 8.7$ & NS \\
\hline
\end{tabular}

ANCOVA was performed to compare the genotype groups. The polymorphism was set as a fixed factor. Age and BMI were added as co-variables to adjust the results. For abbreviations, see Table 2 . Data are presented as mean \pm S.D.
Table 4 Echocardiographic variables in the euglycemic patients according to the $\beta_{1}$ AR Arg389 homozygotes and Gly389 carriers

\begin{tabular}{llll}
\hline & $\begin{array}{l}\text { Euglycemic patients } \\
\mathbf{n}=\mathbf{3 5 9} \text { (79.4\%) } \\
\text { Arg homozygotes } \\
\mathbf{n = 2 0 3} \text { (56.5\%) }\end{array}$ & $\begin{array}{l}\text { Gly carriers } \\
\mathbf{n}=\mathbf{1 5 6}(\mathbf{4 3 . 5 \% )})\end{array}$ & $\mathbf{p}$ value \\
\hline LVMl & $60.6 \pm 17.5$ & $56.3 \pm 19.2$ & 0.028 \\
IVSd (mm) & $13.1 \pm 3.0$ & $12.0 \pm 2.4$ & 0.001 \\
LVIDd (mm) & $49.4 \pm 7.3$ & $49.9 \pm 6.9$ & NS \\
LVPWd (mm) & $12.6 \pm 3.0$ & $12.0 \pm 2.8$ & NS \\
EF & $46.6 \pm 8.5$ & $46.0 \pm 8.4$ & NS \\
\hline
\end{tabular}

The analyses were performed and data are presented as described in Table 3. For abbreviations, see Table 2.

higher among the Arg389 homozygotes compared to the Gly389 carriers $(\mathrm{p}=0.001)$. The calculated powers were $62 \%$ for LVMI (required sample size for the achievement of $80 \%$ power would be again 580 subjects) and as high as $100 \%$ for IVSd.

Table 5 shows that there was no difference in LVMI and IVSd values between the diabetic Arg389 homozygotes and Gly389 carriers. Ejection fraction (EF) was slightly smaller among the Arg389 homozygotes when compared to the Gly389 carriers $(p=0.049)$, but this finding is most likely only random variation because of the small sample size.

\section{Discussion}

The main finding of our study is the apparent association of the $\beta_{1} \mathrm{AR}$ Arg389 homozygotes with $\mathrm{LVH}$ among euglycemic AMI survivors, and that this association does not appear to exist among diabetic AMI survivors. Analyzing 452 Finnish patients who had undergone AMI, $79.4 \%$ of whom were euglycemic and $20.6 \%$ diabetic, we were able to show that the $\beta_{1}$ AR Arg389 homozygotes had significantly higher LVMI when compared to the Gly389 carriers (either Gly389 homozygotes or Arg/Gly389 heterozygotes). The same applied also to IVSd, and this association was even stronger. Our result

Table 5 Echocardiographic variables in the diabetic patients according to the $\beta_{1}$ AR Arg389 homozygotes and Gly389 carriers

\begin{tabular}{llll}
\hline & $\begin{array}{l}\text { Diabetic patients } \\
\mathbf{n}=\mathbf{9 3}(\mathbf{2 0 . 6 \% )} \\
\text { Arg homozygotes } \\
\mathbf{n}=\mathbf{5 5}(\mathbf{5 9 . 1 \% )}\end{array}$ & $\begin{array}{l}\text { Gly carriers } \\
\mathbf{n}=\mathbf{3 8}(\mathbf{4 0 . 9 \% )}\end{array}$ & $\mathbf{p}$ value \\
\hline LVMI & $70.3 \pm 22.8$ & $67.2 \pm 20.3$ & NS \\
IVSd (mm) & $13.4 \pm 3.3$ & $13.5 \pm 3.3$ & NS \\
LVIDd (mm) & $51.1 \pm 7.5$ & $49.6 \pm 6.5$ & NS \\
LVPWd (mm) & $13.9 \pm 5.2$ & $14.6 \pm 5.5$ & NS \\
EF & $43.3 \pm 9.0$ & $46.9 \pm 9.8$ & 0.049 \\
\hline
\end{tabular}

The analyses were performed and data are presented as described in Table 3. For abbreviations, see Table 2 . 
is logical based on previous reports on the functional properties of the two receptor variants. The $\beta_{1} A R$ Arg389 variant has been shown to display markedly increased coupling to $G_{s}$ and stimulation of adenylyl cyclase in response to the agonist isoproterenol in vitro as compared to the Gly389 receptor form [21]. Gly389 is thought to disrupt the predicted alpha-helical region of the cytoplasmic carboxyl terminus of the receptor, which may cause a less favorable receptor conformation for coupling to $G_{s}$ [28]. Thus, the $\beta_{1} A R$ Arg389 variant can be considered as a "gain-of-function" receptor form.

It is well known that prolonged activation of the $\beta_{1} \mathrm{AR}$ leads to worsening of cardiac function. As a consequence, $\beta_{1}$ AR expression is down-regulated and its coupling to adenylyl cyclase is desensitized [29]. The Arg389Gly polymorphism appears to modulate this pathological situation: Mialet Perez et al., who used transgenic mice, showed that the Arg389 variant is impaired in down-regulation, which most likely represents a protective event in the failing myocardium. Furthermore, the young Arg389 mice were found to have enhanced receptor function and heart contractility compared to the Gly389 carriers, whereas the older Arg389 mice displayed a phenotypic switch with decreased signalling to adenylyl cyclase and contractility compared to the corresponding Gly389 mice [30]. In line with these in vivo studies, Rathz et al. have shown that the $\beta_{1} \mathrm{AR}$ Arg389 variant undergoes less agonist-promoted desensitization in vitro compared to its allelic counterpart [31]. Recently, Lewin and colleagues have thrown light on the mechanism underlying the $\beta_{1} \mathrm{AR}$-induced cardiac damage by showing that inactivation of the cyclic AMP response element modulator (CREM) rescued the $\beta_{1} \mathrm{AR}$-overexpressing mice from cardiomyocyte hypertrophy, fibrosis, and left ventricular dysfunction [32]. It would be interesting to know, whether there is a difference in CREM expression and/or function between individuals carrying either the Arg389 or Gly389 variant - a highly speculative possibility worth investigating.

Our results support the notion that there is a direct genetic impact of the $\beta_{1}$ AR Arg389 homozygosity on the left ventricular structure. We cannot, however, rule out the possibility that the observed increases in LVMI and IVSd among the $\beta_{1} \mathrm{AR}$ Arg389 homozygotes were related to hypertension because LVH partly represents an adaptive response to hypertension [33]. In previous studies it has been shown that the $\beta_{1}$ AR Arg389 homozygotes have an increased risk to develop essential hypertension among Scandinavians [34] and Chinese [35]. We, nevertheless, did not detect higher blood pressure values among the Arg389 homozygotes as compared to the Gly389 carriers in our study population (data not shown). This negative finding most likely results from the anti-hypertensive medication of the patients that took place after AMI and hospitalization and/or from the relatively small sample size.

To our knowledge, there are four previous studies concerning the $\beta_{1}$ AR Arg389Gly polymorphism and left ventricular structure. In accordance with our study, $\mathrm{Fu}$ et al. described a significant association between the $\beta_{1}$ AR Arg389 variant and LVH in Chinese hypertensive individuals in two independent populations $(\mathrm{n}=2417$ and $\mathrm{n}=327$ ) [13]. In contrast, no relationship between LVM and the $\beta_{1}$ AR Arg389Gly polymorphism was found in a study population consisting of 110 healthy Caucasian twin pairs $(n=220)$ [12]. In a third study by Stanton and colleagues, the Gly389 homozygotes were observed to have higher LVM when compared to the Arg389 homozygotes among 249 Caucasian patients suffering from renal failure [14]. This study consisted of a very specific population: each individual had a proven renal disease, $37 \%$ of whom were on renal replacement therapy. This may explain the result that seems physiologically counter-intuitive. In the fourth study, Meyers et al. who studied African American siblings suffering from hypertension found no significant association between the $\beta_{1}$ AR Arg389Gly polymorphism and LVMI but reported that the Gly389 allele was significantly associated with a higher mean relative wall thickness compared to the Arg389 form [15]. This association was not replicated in another study group consisting of a Hispanic cohort. It is important to note that the Gly389 allele is more frequent in black populations [15,25], which may explain the divergent findings.

When we analyzed the euglycemic and diabetic patients of our study group separately, we did not find any association between the $\beta_{1} \mathrm{AR}$ Arg389Gly polymorphism and LVH among the diabetic patients. The negative result can be considered to arise from an independent association between DM and LVH [2-6], which is presumably stronger than the association of the $\beta_{1} A R$ Arg389Gly polymorphism with LVH. Therefore the assumed stronger effect of DM can be expected to mask the weaker effect of the polymorphism on the left ventricular structure. Interestingly, the association between $\mathrm{DM}$ and LVH seems to be stronger in women than in men $[2,5,6]$. In our study population the proportion of women was significantly higher among the diabetic subgroup as compared to the non-diabetics one (30.1/ $19.5 \%)$, supporting the hypothesis of the aforementioned "masking effect" of DM. Furthermore, the $\beta_{1}$ AR expression has been shown to be markedly decreased in the hearts of diabetic patients (atrial appendages) [36], which may also have had an impact on our results.

\section{Limitations}

Evaluating left ventricular parameters from post-AMI patients with two-dimensional guided M-mode 
echocardiography is not always reliable if the infarction happens to be in the area where the measures are being taken from. Determining the EF with the M-mode device has also limitations, because the systolic function is measured only from a single point of the left ventricle. Furthermore, in our study, echocardiography was performed within one week after AMI, and consequently hyperaemia may have contributed to the measurements in addition to the left ventricular dysfunction and remodeling. Additionally, the amount of diabetic patients was rather small in our study sample, which causes certain limitations to the statistic analyses.

\section{Conclusions}

As a conclusion, we show here that LVMI and IVSd values are significantly higher among AMI survivors who are homozygous for the $\beta_{1}$ AR Arg389 variant compared to the AMI patients carrying either one or two copies of the Gly389 allelic form of the $\beta_{1} \mathrm{AR}$. The $\beta_{1} \mathrm{AR}$ Arg389 variant thus seems to confer higher risk of developing LVH. In addition, we show that the aforementioned association is not universal, since it does not exist among diabetic AMI survivors. We hypothesize that this negative finding is caused by the strong association between DM and $\mathrm{LVH}$, which may mask the presumably weaker effect of the $\beta_{1}$ AR Arg389 variant on the left ventricular structure.

\section{Abbreviations}

ANCOVA: analysis of covariance; AMI: acute myocardial infarction; $\beta_{1}$ AR: beta1 adrenergic receptor; BMl; body mass index; DM: diabetes mellitus; EF: ejection fraction; IVSd; interventricular septal thickness at end-diastole; LVH: left ventricular hypertrophy; LVIDd: left ventricular internal dimension at enddiastole; LVM: left ventricular mass; LVMI: left ventricular mass index; LVPWd: left ventricular posterior wall thickness at end-diastole

\section{Acknowledgements}

This work was supported by the Finnish Foundation for Cardiovascular Research and the Finnish Medical Society Duodecim (AEH); Fondation Leducq (Paris, France), the Science Foundation of Instrumentarium and the Finnish Cultural Foundation (JMJ); the Sigrid Juselius Foundation (HVH) (UEPR) and Academy of Finland (\#127199, UEP-R). We thank M.D. Antti Hakalahti and M.D. Olli-Pekka Piira for a critical review of the manuscript, laboratory technicians Päivi Kastell and Miia Vierimaa for extracting the DNA from blood samples and for the help in genotyping, respectively, and M.Sc. Risto Bloigu and M.Sc. Annaleena Okuloff for the advice in statistical analyses.

\section{Author details}

${ }^{1}$ Institute of Biomedicine, Department of Anatomy and Cell Biology, University of Oulu, P.O. Box 5000, Fl-90014 Oulu, Finland. ²Department of Cardiology, Helsinki University Central Hospital, Fl-00290 Helsinki, Finland. ${ }^{3}$ Institute of Clinical Medicine, Department of Internal Medicine, Division of Cardiology, University of Oulu, P.O. Box 5000, Fl-90014 Oulu, Finland.

\section{Authors' contributions}

AEH carried out the genotyping of patients, performed the statistical analyses and drafted the manuscript. JMT performed the echocardiography. JMJ, KSK and HVH critically reviewed the manuscript. UEP-R critically reviewed the manuscript and helped to draft it. All authors read and approved the final manuscript.

\section{Competing interests}

The authors declare that they have no competing interests.

Received: 15 June 2010 Accepted: 23 August 2010

Published: 23 August 2010

\section{References}

1. Ghali JK, Liao Y, Simmons B, Castaner A, Cao G, Cooper RS: The prognostic role of left ventricular hypertrophy in patients with or without coronary artery disease. Ann Intern Med 1992, 117:831-836.

2. Galderisi M, Anderson KM, Wilson PW, Levy D: Echocardiographic evidence for the existence of a distinct diabetic cardiomyopathy (the Framingham Heart Study). Am J Cardiol 1991, 68:85-89.

3. Lee M, Gardin JM, Lynch JC, Smith V-E, Tracy RP, Savage PJ, Szklo M, Ward BJ: Diabetes mellitus and echocardiographic left ventricular function in free-living elderly men and women: The Cardiovascular Health Study. Am Heart J 1997, 133:36-43.

4. Devereux RB, Roman MJ, Paranicas M, O'Grady MJ, Lee ET, Welty TK, Fabsitz RR, Robbins D, Rhoades ER, Howard BV: Impact of diabetes on cardiac structure and function: the strong heart study. Circulation 2000, 101:2271-2276.

5. Ilercil A, Devereux RB, Roman MJ, Paranicas M, O'Grady MJ, Welty TK, Robbins DC, Fabsitz RR, Howard BV, Lee ET: Relationship of impaired glucose tolerance to left ventricular structure and function: The Strong Heart Study. Am Heart J 2001, 141:992-998.

6. Tenenbaum A, Fisman EZ, Schwammenthal E, Adler Y, Benderly M, Motro M, Shemesh J: Increased prevalence of left ventricular hypertrophy in hypertensive women with type 2 diabetes mellitus. Cardiovasc Diabetol 2003, 2:14.

7. Tanase $H$, Yamori $Y$, Hansen $C T$, Lovenberg $W$ : Heart size in inbred strains of rats. Part 1. Genetic determination of the development of cardiovascular enlargement in rats. Hypertension 1982, 4:864-872.

8. Nunez DJ, Clifford CP, al-Mahdawi S, Dutka D: Hypertensive cardiac hypertrophy-is genetic variance the missing link? Br J Clin Pharmacol 1996, 42:107-117.

9. Schunkert H, Brockel U, Hengstenberg C, Luchner A, Muscholl MW, Kurzidim K, Kuch B, Doring A, Riegger GA, Hense HW: Familial predisposition of left ventricular hypertrophy. J Am Coll Cardiol 1999, 33:1685-1691.

10. Bella JN, MacCluer JW, Roman MJ, Almasy L, North KE, Best LG, Lee ET, Fabsitz RR, Howard BV, Devereux RB: Heritability of left ventricular dimensions and mass in American Indians: The Strong Heart Study. $J$ Hypertens 2004, 22:281-286.

11. Post WS, Larson MG, Myers RH, Galderisi M, Levy D: Heritability of left ventricular mass: the Framingham Heart Study. Hypertension 1997 30:1025-1028

12. Swan L, Birnie DH, Padmanabhan S, Inglis G, Connell JM, Hillis WS: The genetic determination of left ventricular mass in healthy adults. Eur Heart J 2003, 24:577-582.

13. Fu C, Wang H, Wang S, Shi $Y$, Zhou $X$, Sun $K$, Chen J, Song $X$, Xue H, Hui R: Association of beta 1-adrenergic receptor gene polymorphisms with left ventricular hypertrophy in human essential hypertension. Clin Biochem 2008, 41:773-778.

14. Stanton $T$, Inglis GC, Padmanabhan S, Dominiczak AF, Jardine AG, Connell JM: Variation at the beta-1 adrenoceptor gene locus affects left ventricular mass in renal failure. J Nephrol 2002, 15:512-518.

15. Meyers KJ, Mosley TH, Fox E, Boerwinkle E, Arnett DK, Devereux RB, Kardia SLR: Genetic variations associated with echocardiographic left ventricular traits in hypertensive blacks. Hypertension 2007, 49:992-999.

16. Brodde OE: Beta 1- and beta 2-adrenoceptors in the human heart: properties, function, and alterations in chronic heart failure. Pharmacol Rev 1991, 43:203-242.

17. Hoehe MR, Otterud B, Hsieh WT, Martinez MM, Stauffer D, Holik J, Berrettini WH, Byerley WF, Gershon ES, Lalouel JM, et al: Genetic mapping of adrenergic receptor genes in humans. J Mol Med 1995, 73:299-306.

18. Frielle T, Collins S, Daniel KW, Caron MG, Lefkowitz RJ, Kobilka BK: Cloning of the CDNA for the human beta 1-adrenergic receptor. Proc Natl Acad Sci USA 1987, 84:7920-7924.

19. Maqbool A, Hall AS, Ball SG, Balmforth AJ: Common polymorphisms of beta1-adrenoceptor: identification and rapid screening assay. Lancet 1999, 353:897. 
20. O'Dowd BF, Hnatowich M, Regan JW, Leader WM, Caron MG, Lefkowitz RJ: Site-directed mutagenesis of the cytoplasmic domains of the human beta 2-adrenergic receptor. Localization of regions involved in $\mathrm{G}$ protein-receptor coupling. J Biol Chem 1988, 263:15985-15992.

21. Mason DA, Moore JD, Green SA, Liggett SB: A gain-of-function polymorphism in a G-protein coupling domain of the human $\beta_{1^{-}}$ adrenergic receptor. J Biol Chem 1999, 274:12670-12674.

22. Tapanainen JM, Still AM, Airaksinen KE, Huikuri HV: Prognostic significance of risk stratifiers of mortality, including $T$ wave alternans, after acute myocardial infarction: results of a prospective follow-up study. J Cardiovasc Electrophysiol 2001, 12:645-652.

23. Devereux RB, Alonso DR, Lutas EM, Gottlieb GJ, Campo E, Sachs I, Reichek N: Echocardiographic assessment of left ventricular hypertrophy: comparison to necropsy findings. Am J Cardiol 1986, 57:450-458.

24. Rothman KJ: No adjustments are needed for multiple comparisons. Epidemiology 1990, 1:43-46.

25. Moore JD, Mason DA, Green SA, Hsu J, Liggett SB: Racial differences in the frequencies of cardiac beta(1)-adrenergic receptor polymorphisms: analysis of c145A > G and c1165G > C. Hum Mutat 1999, 14:271.

26. White HL, Maqbool A, McMahon AD, Yates L, Ball SG, Hall AS, Balmforth AJ: An evaluation of the beta-1 adrenergic receptor Arg389Gly polymorphism in individuals at risk of coronary events. A WOSCOPS substudy. Eur Heart J 2002, 23:1087-1092.

27. Tesson F, Charron P, Peuchmaurd M, Nicaud V, Cambien F, Tiret L, Poirier O, Desnos $M$, Jullieres $Y$, Amouyel $P$, et al: Characterization of a unique genetic variant in the beta1-adrenoceptor gene and evaluation of its role in idiopathic dilated cardiomyopathy. CARDIGENE Group. J Mol Cell Cardiol 1999, 31:1025-1032.

28. Small KM, McGraw DW, Liggett SB: Pharmacology and physiology of human adrenergic receptor polymorphisms. Annu Rev Pharmacol Toxicol 2003, 43:381-411.

29. Bristow MR, Hershberger RE, Port JD, Minobe W, Rasmussen R: Beta 1- and beta 2-adrenergic receptor-mediated adenylate cyclase stimulation in nonfailing and failing human ventricular myocardium. Mol Pharmacol 1989, 35:295-303.

30. Mialet Perez J, Rathz DA, Petrashevskaya NN, Hahn HS, Wagoner LE, Schwartz A, Dorn GW, Liggett SB: Beta 1-adrenergic receptor polymorphisms confer differential function and predisposition to heart failure. Nat Med 2003, 9:1300-1305.

31. Rathz DA, Gregory KN, Fang Y, Brown KM, Liggett SB: Hierarchy of polymorphic variation and desensitization permutations relative to beta 1- and beta 2-adrenergic receptor signaling. J Biol Chem 2003, 278:10784-10789.

32. Lewin G, Matus M, Basu A, Frebel K, Rohsbach SP, Safronenko A, Seidl MD, Stümpel F, Buchwalow I, König $S$, et al: Critical role of transcription factor cyclic AMP response element modulator in beta1-adrenoceptormediated cardiac dysfunction. Circulation 2009, 119:79-88.

33. Savage DD, Drayer JI, Henry WL, Mathews EC Jr, Ware JH, Gardin JM, Cohen ER, Epstein SE, Laragh JH: Echocardiographic assessment of cardiac anatomy and function in hypertensive subjects. Circulation 1979, 59:623-632.

34. Bengtsson K, Melander O, Orho-Melander M, Lindblad U, Ranstam J, Rastam L, Groop L: Polymorphism in the beta(1)-adrenergic receptor gene and hypertension. Circulation 2001, 104:187-190.

35. Peng Y, Xue H, Luo L, Yao W, Li R: Polymorphisms of the beta1adrenergic receptor gene are associated with essential hypertension in Chinese. Clin Chem Lab Med 2009, 47:1227-1231.

36. Dinçer UD, Tay A, Arioglu E, Tašdelen A, Ašlamaci S, Bidasee KR: Decreased expression of beta1- and beta2-adrenoceptors in human diabetic atrial appendage. Cardiovasc Diabetol 2003, 2:6.

doi:10.1186/1475-2840-9-42

Cite this article as: Hakalahti et al:: Association of the beta- 1 adrenergic receptor carboxyl terminal variants with left ventricular hypertrophy among diabetic and non-diabetic survivors of acute myocardial infarction. Cardiovascular Diabetology 2010 9:42.

\section{Submit your next manuscript to BioMed Central and take full advantage of:}

- Convenient online submission

- Thorough peer review

- No space constraints or color figure charges

- Immediate publication on acceptance

- Inclusion in PubMed, CAS, Scopus and Google Scholar

- Research which is freely available for redistribution

Submit your manuscript at www.biomedcentral.com/submit
Biomed Central 